\title{
Impromptu Speech for Strengthening Tertiary Students' Oral Communication Competencies in Large Classes
}

\author{
Khadija Sekkal
}

Department of English, Faculty of Letters and Human Sciences, Sais, Sidi Mohamed Ben Abdellah University Fez, Morocco.

\begin{abstract}
Being an accomplished oral communicator is recognized as the hallmark of competent EFL tertiary students. Yet, many students after their graduation, especially from open access colleges with large cohorts, fail to be equipped with adequate oral communication competencies. The present study suggests individual impromptu talks as a strategy for improving students' oral communication skills in large classes. To test the efficiency of this strategy, a quasi-experimental design was conducted at Sidi Mohamed Ben Abdellah University, Faculty of Letters and Humanities, Sais-Fez, Morocco involving 15 students in the experimental class and 15 students in the control class. Treatment was done using: impromptu speech technique for the experimental group (Group 1) and the conventional teaching method using oral presentations technique for the control group (Group 2). The results show that students using impromptu talks are far better than those using the conventional method of teaching oral communication skills. These students have considerably succeeded in maintaining constant, coherent talks featured by correct pronunciation, appropriate vocabulary, and well-formed sentences. They have also acquired how to be good listeners and sensible users of non-verbal communication. The study, therefore, underlines the efficiency of impromptu talks for honing EFL students' oral communication skills at open access colleges.
\end{abstract}

Keywords - EFL tertiary students, oral communication skills, impromptu speech, large classes.

\section{INTRODUCTION}

Oral communication skills are primordial for English as a Foreign Language (EFL) tertiary students to succeed in their academic as well as professional life (Hetherington 1980, Mahmud 2014, Tsang 2017). For this reason, being an accomplished oral communicator remains for them a top-priority. In Moroccan universities, several courses have been designed to enhance EFL students' oral communication competencies, namely oral communication, Spoken English, business communication, and public speaking and debating. However, when students graduate, they oftentimes find difficulties to express their ideas clearly, select proper vocabulary, pronounce well, listen effectively, and use their body language correctly. Furthermore, they constantly undergo speech apprehension and lack of self-confidence.

Many studies, including Bailey (2005), Goh (2007), and Aliyu (2017), have put forward some strategies, situations, and activities for enhancing students' oral communication competencies. These scholars have underlined the role of collaborative learning which is particularly dependent on cooperative group work and pair work activities. Rahman (2010), likewise, recommended a task-based approach for developing students' oral communication skills based on role-play, individual oral presentations, and group discussion involving up to five students. All these proposed strategies emphasize small classes as a prerequisite. However, the availability of such classes at open access colleges, such as Sidi Mohamed Ben Abdellah University, Faculty of Letters and Human Sciences, Sais Fez, stands as a stumbling block for implementing effective student-student interaction and maintaining cooperative and collaborative group work. Accommodating as many as 150 students, the faculty's auditoriums/large classrooms remain wide open for learners to attend at any time during course sessions assigned to enhance their oral communication skills. Instructors, thus, have little control over their large classes due to many students' tardiness, untimely departures, and absenteeism. As a result, student attention is often distracted away from communicative tasks. Furthermore, instructors frequently opt for traditional group/individual oral presentations which do not give the chance for the 
majority of students to experience standing in front of their peers and communicate in English. Auditoriums, hence, provide undergraduates with insufficient or no speaking practice and limit instructors' ability to monitor practice through individualized attention. In view of this, individual impromptu speech is suggested as a strategy for improving students' oral communication skills. To test the efficiency of this strategy, a quasi-experimental research is adopted in this paper which tries to give detailed answers to the following questions:

1- Is impromptu speech an effective strategy for enhancing students' oral competencies in open access large classes?

2- Does it display students' abilities most?

3- Are EFL learners more actively engaged through impromptu talks?

The participants of this study are EFL first-year students and the course under study is Oral Communication considered as the basic foundation for mastering oral communication skills.

\section{REVIEW OF LITERATURE}

Oral communication skills stand pivotal for EFL tertiary students (Hetherington 1980, Tsang 2014, Mahmud 2017). They inevitably help them operate in the real world. They effectively impact on their level of success as they provide confidence in a wide range of situations--personal, academic, and professional--ranging from informal exchanges between friends and family members to formal speeches such as lectures and conference papers. Oral communication commonly refers to a two-way process between speaker and listener, incorporating, therefore, the productive skill of speaking and the receptive skill of listening (Byrne 1986, Alwright 1994, Brown 1994). Speaking, which involves the construction and delivery of information through the mouth, is described by Syakur (1987: 5) as a complex skill since it necessitates not less than the components of four skills. These skills, according to him, are grammar, vocabulary, pronunciation, and fluency; they undoubtedly help speakers to express their thoughts clearly and therefore be understood easily. Listening, on the other hand, is the ability to accurately receive and understand messages. It is a critical skill that necessitates "paying a close attention to a speaker's accent, grammar, and vocabulary to understand their message" (Sekkal 2020: 37). It is thanks to it that human relationships are underpinned. Both speaking and listening, thus, stand as "lifelong activities and [are] probably our most important communication tool" (Staab 1992: 6) as they energize participating in discussions, exchanging information, expressing thoughts, and interacting with different people.

Effectiveness in oral communication depends not only on being an active listener or a competent speaker displaying fluency, appropriate command of vocabulary and syntactic forms, as well as proper pronunciation, but also on using adequate "symbols and gestures that accompany the spoken words" (Rahman 2010: 3). Oral communication is never isolated but always adjunct to nonverbal communication. In the same line of argumentation, Merhabian and Ferris (1967) assert that we have three channels of communication: our words, our voice tone, and our body language. According to them, 7\% represents our verbal communication; however, $93 \%$ represents our nonverbal communication. $93 \%$ is the total sum of voice tone $(38 \%)$ and body language (55\%). Non-verbal communication is conveyed by paralanguage, namely pitch, volume, intonation, and tempo, and by kinesics including, among other things, gestures, oculesics, facial expressions, and posture.

Many studies associate oral communication ability to speech practice (Brown \& Bennet 2002, Moors \& De Houwer 2006, Anderson 2008). Ayres et al. (1998: 176) stress that oral communication is learnt and refined through speech practice "associated with reduced apprehension and a higher degree of willingness to deliver speeches". Practicing speech a multitude of times, especially before actual delivery, tests out speakers' performance and helps them find errors and make possible adjustments in a safe environment. Furthermore, it provides them with ample reassurance and helps them manipulate their speech and actions. In the same vein, Smith \& Frymier (2006) confirm the importance of speech practice. They talk about its effectiveness in front of a mirror, in front of a small audience, and then in front of a large audience. Yet, they assert that speech delivery in front of a larger audience is the most effective speech practice as it is more realistic. Goffman (1981) mentions three modes of speech delivery. Firstly, 'memorization', also known as extemporaneous, is based on thorough preparation, rehearsal, and delivery by rote. Secondly, 'aloud reading' is the word-for-word iteration of a written manuscript at lectures and conferences. Finally, fresh talk is also labeled impromptu speech which is delivered on the spur of the moment.

Impromptu speech is a "method of delivery that has very little, if any, preparation or rehearsal (Ford-Brown 2014: 223). It is also called spontaneous speech, off-thecuff speech, and think on your feet speech as the speaker gives a talk on the spot about a topic they are quite knowledgeable about. Like any other speech, it has an introduction, body, and conclusion and takes place in 
formal and informal settings. Impromptu speech is "a relatively simple formal speaking exercise of a limited duration of time" (Henderson 1982: 76). It involves no more than seven minutes devoted to topic selection, organization of ideas, and delivery.

Many researchers have acknowledged the importance of impromptu speech as it helps students hone their oral communication skills. It is regarded by Girardelli (2017) as a form of competition for students since it heartens them to defeat all the difficulties embedded in this challenging form of speech. In fact, it helps students organize their ideas logically (Henderson 1982) and enhance the ability to put thoughts together on the spot (Billings \& Billings 2010). Moreover, it allows students to speak informatively and confidently about a variety of topics (Barruansyah 2018) and prepares them to communicate on the spur of the moment (Preston 1990). Impromptu talks are also a means of attenuating students' public speaking anxiety and improving speech delivery skills (El Mortaji 2017).

Apart from developing students' speaking skills (Lumettu \& Runtuwene 2018) and their appropriate use of non-verbal communication, including body language and paralanguage (Henderson 1982, El Mortaji 2017), impromptu speech teaches students to focus their listening skills (Mbeh 2017). In class, students are required to listen actively to their classmates' impromptu talks and provide feedback. Accordingly, impromptu speech is regarded, by many researchers, as the wherewithal to hone students' speaking, listening, and non-verbal communication.

\section{METHODOLOGY}

The present study, a quasi-experimental design based on volunteer sampling, was carried out at Sidi Mohamed Ben Abdellah University, Faculty of Letters and Humanities, Sais-Fez, Morocco. The implementation of this research took place from mid -January until the end of April 2019. The study was conducted throughout the duration of Oral Communication course whose main objective is to enhance students' oral communication skills.

\subsection{ORAL COMMUNICATIO COURSE}

Oral Communication Course is offered as a mandatory course for first-year undergraduates in the second semester. It is usually taught for two hours and thirty minutes once a week over a period of fourteen weeks. It covers monitoring participation in discussions, informal talks, and formal speeches. The course objectives are designed to improve students' speaking skills and to update the competencies needed for participating in discussions. The course also aims to improve listening skills and strategies involved in academic and colloquial English, and help students manipulate their non-verbal communication.

Upon successful completion of the course, students are expected to:

1. Identify their personal communication style and their communication strengths as well as weaknesses.

2. Increase speech confidence and/or reduce communication stress.

3. Critically analyze and evaluate their own and their peers' performance.

4. Recognize how body language and other non-verbal cues convey unconscious messages.

5. Customize delivery in accordance with audience specifics and adjust communication style.

6. Identify several techniques for enhancing their listening, response, and feedback skills.

7. Demonstrate better ability to communicate effectively in a variety of settings including college, workplace, and eventually home.

To reach these learning outcomes, students were taught the skills required for delivering impromptu talks and oral presentations, including careful planning, good time management, establishing good rapport with the audience, and using adequate, proper body language, voice quality, and simple language. They were also instructed some guidelines for enhancing their listening skills, controlling their fear, mitigating their apprehension, and boosting their motivation as well as self-confidence. Different assignments on pronunciation, vocabulary, grammar, namely homophones, homographs, and idioms were devised to students. They were also encouraged to allow sufficient time for practicing these skills at home to identify any weak points.

\subsection{PARTICIPANTS}

The participants of the study were first-year English department students. Out of more than 300 Oral Communication course students divided into two groups, only 30 volunteered and showed their dedication to attend the course regularly. They were grouped into two different classes: 15 students in Group 1 representing the experimental class and 15 students in Group 2 representing the control class. Treatment was done for Group 1 using impromptu speech technique. For Group 2, the conventional technique of delivering oral presentations was used. 
Students of both groups were instructed to take an active part in class discussions and debates. Besides, they were tutored into the same content with increased emphasis on impromptu talks for group 1 and oral presentations for group 2. Group 1 students were required to give a 5 to 7 minute impromptu speech, and group 2 were asked to give less than a 10 minute individual oral presentation.

\subsection{INSTRUMENTS}

Pre and post-tests were designed for the experimental and control groups. They were meant to assess participants' oral communication skills via direct observation of their performance. Both tests focused on assessing students' pronunciation in terms of word/sentence stress, pitch, intonation, as well as ability to produce intelligible speech. Fluency was also emphasized, including continuous, coherent, and cohesive talk, involving appropriate vocabulary together with grammar. Participants' listening skills along with their non-verbal communication, particularly kinesics, oculesics, and vocalic were also evaluated.

The pre-test was given to students before dividing them into two groups. The purpose of the pre-test was to divide the students equally according to their results and to compare and explore the oral communication skills of both groups later. After 35 contact hours over a period of 14 weeks, the post-test was set to see if there is any difference between the two groups who shared the same level before using treatment. It is meant to evaluate students' oral competencies development after the treatment. In other words, it was adopted to investigate the effectiveness of the proposed impromptu speech technique for enhancing oral communication skills.

Both tests adopted the grading scale of 0-20 in pronunciation, fluency, vocabulary along with grammar, listening, and non-verbal communication. The whole test was scored out of 100 according to the Moroccan grading system: (1-30): very poor, (31-49): poor, (50-59): fair, (6069): Good, (70-79): very good, and (80-100): excellent.

\section{DATA ANALYSIS AND DISCUSSION}

This part presents and discusses the results of both pre and post-tests. Firstly, it discusses the pre-test results of the experimental and control groups. Secondly, it explores the post-tests of both the experimental and control groups, and then compares between the results of the two tests to see if there is any progress achieved to be attributed to the technique of impromptu speech.

\subsection{PRE-TEST RESULTS}

The first step in data analysis is to see the difference between the results of the pre-test of the experimental and control groups. The pre-test results of both groups are illustrated in figures 1 and 2 . They represent the results of the experimental and control groups respectively. They show their grades in detail in the four skills of speaking, namely pronunciation, fluency, vocabulary as well as grammar, listening, and non-verbal communication. The overall grade is out of 100 .

\begin{tabular}{|c|c|c|c|c|c|c|}
\hline Sample & Pronunciation & Fluency & $\begin{array}{l}\text { Vocabulary/ } \\
\text { Grammar }\end{array}$ & Listening & $\begin{array}{c}\text { Non-verbal } \\
\text { Communication }\end{array}$ & Total \\
\hline 1 & 8 & 6 & 10 & 6 & 10 & 40 \\
\hline 2 & 6 & 5 & 8 & 9 & 7 & 35 \\
\hline 3 & 10 & 11 & 12 & 11 & 12 & 56 \\
\hline 4 & 5 & 8 & 6 & 8 & 7 & 34 \\
\hline 5 & 2 & 4 & 4 & 2 & 3 & 15 \\
\hline 6 & 11 & 11 & 12 & 13 & 10 & 57 \\
\hline 7 & 13 & 12 & 13 & 14 & 13 & 65 \\
\hline 8 & 7 & 8 & 8 & 12 & 9 & 44 \\
\hline 9 & 7 & 5 & 6 & 8 & 7 & 33 \\
\hline 10 & 9 & 10 & 10 & 9 & 11 & 49 \\
\hline 11 & 8 & 8 & 7 & 10 & 9 & 42 \\
\hline 12 & 10 & 12 & 10 & 12 & 11 & 55 \\
\hline 13 & 4 & 6 & 6 & 4 & 5 & 25 \\
\hline 14 & 12 & 13 & 10 & 12 & 11 & 58 \\
\hline 15 & 9 & 10 & 10 & 12 & 11 & 52 \\
\hline
\end{tabular}

Fig.1: The pre-test results of the experimental group 


\begin{tabular}{ccccccc}
\hline Sample & Pronunciation & Fluency & $\begin{array}{c}\text { Vocabulary/ } \\
\text { Grammar }\end{array}$ & Listening & $\begin{array}{c}\text { Non-verbal } \\
\text { Communication }\end{array}$ & Total \\
\hline 1 & 6 & 5 & 7 & 6 & 8 & 32 \\
2 & 10 & 12 & 10 & 11 & 9 & 52 \\
3 & 5 & 4 & 5 & 7 & 6 & 27 \\
4 & 10 & 8 & 10 & 11 & 10 & 49 \\
5 & 8 & 7 & 9 & 10 & 10 & 44 \\
6 & 9 & 11 & 10 & 12 & 11 & 53 \\
7 & 12 & 12 & 13 & 11 & 13 & 61 \\
8 & 2 & 4 & 3 & 5 & 4 & 18 \\
9 & 6 & 5 & 7 & 7 & 4 & 29 \\
10 & 9 & 11 & 11 & 9 & 10 & 50 \\
11 & 12 & 10 & 9 & 10 & 8 & 49 \\
12 & 8 & 9 & 10 & 9 & 7 & 43 \\
13 & 7 & 8 & 6 & 5 & 5 & 31 \\
14 & 13 & 12 & 14 & 13 & 13 & 65 \\
15 & 12 & 11 & 12 & 12 & 10 & 57 \\
\hline
\end{tabular}

Fig.2: The pre-test results of the control group

In the experimental group, two students were very poor, seven students were poor, five students were fair, and one student was good. However, none was very good or excellent. Correspondingly, in the control group, three students were very poor, six students were poor, four students were fair, and two students were good. Yet, none was very good or excellent.

As deduced in the results of the pre-test of both groups, the students' oral communication skills before they were given treatment were generally poor and relatively fair. Their performance was low and to some extent unsatisfactory. They found difficulties in speaking continuously for a few minutes. Their pronunciation was oftentimes incorrect, their vocabulary was limited, and their language mistakes were conspicuous. Like their speaking skills, their listening skills were inadequate. They had difficulty listening to and understanding even relatively brief messages. They were not confident enough and their shyness was also displayed in their body posture, lack of eye contact, facial expressions, and gestures. Generally, their apprehension and anxiety were more apparent in their performance.

\section{4-2 POST-TEST RESULTS}

The following figures show the post-test results of the experimental and control groups.

\begin{tabular}{ccccccc}
\hline Sample & Pronunciation & Fluency & $\begin{array}{c}\text { Vocabulary/ } \\
\text { Grammar }\end{array}$ & Listening & $\begin{array}{c}\text { Non-verbal } \\
\text { Communication }\end{array}$ & Total \\
\hline 1 & 10 & 9 & 12 & 11 & 12 & 54 \\
2 & 9 & 9 & 10 & 12 & 10 & 50 \\
3 & 13 & 13 & 14 & 14 & 13 & 67 \\
4 & 8 & 10 & 8 & 10 & 8 & 44 \\
5 & 5 & 7 & 8 & 8 & 7 & 35 \\
6 & 12 & 12 & 14 & 16 & 14 & 68 \\
7 & 14 & 14 & 15 & 16 & 15 & 74 \\
8 & 10 & 10 & 11 & 13 & 11 & 55 \\
9 & 9 & 8 & 7 & 10 & 7 & 41 \\
\hline
\end{tabular}




\begin{tabular}{lcccccc}
\hline 10 & 10 & 11 & 11 & 12 & 11 & 55 \\
11 & 11 & 10 & 10 & 10 & 10 & 51 \\
12 & 13 & 14 & 13 & 15 & 13 & 68 \\
13 & 8 & 9 & 9 & 9 & 8 & 43 \\
14 & 13 & 14 & 12 & 13 & 12 & 64 \\
15 & 10 & 12 & 13 & 15 & 13 & 63
\end{tabular}

Fig.3: The post-test results of the experimental group

\begin{tabular}{ccccccc}
\hline Sample & Pronunciation & Fluency & $\begin{array}{c}\text { Vocabulary/ } \\
\text { Grammar }\end{array}$ & Listening & $\begin{array}{c}\text { Non-verbal } \\
\text { Communication }\end{array}$ & Total \\
\hline 1 & 7 & 6 & 7 & 7 & 9 & 36 \\
2 & 6 & 7 & 8 & 8 & 7 & 36 \\
3 & 5 & 6 & 6 & 7 & 6 & 30 \\
4 & 11 & 8 & 10 & 12 & 10 & 51 \\
5 & 8 & 7 & 9 & 10 & 10 & 44 \\
6 & 9 & 11 & 10 & 12 & 11 & 53 \\
7 & 7 & 6 & 7 & 8 & 8 & 36 \\
8 & 4 & 5 & 4 & 5 & 4 & 22 \\
9 & 6 & 5 & 7 & 7 & 4 & 29 \\
10 & 10 & 12 & 11 & 9 & 10 & 52 \\
11 & 13 & 11 & 10 & 10 & 10 & 54 \\
12 & 8 & 9 & 10 & 10 & 7 & 44 \\
13 & 8 & 8 & 6 & 6 & 5 & 33 \\
14 & 13 & 13 & 14 & 13 & 13 & 66 \\
15 & 13 & 12 & 12 & 12 & 10 & 59 \\
\hline
\end{tabular}

Fig.4: The post-test results of the control group

In the experimental group, no student was very poor. Five students were poor, four students were fair, five students were good, and one student was very good. Yet, none was excellent. On the other hand, in the control group, two students were very poor, six students were poor, four students were fair, and one student was good. Yet, none was very good or excellent.

Post-test results revealed that there was conspicuous progress in the experimental group. Students considerably improved their pronunciation, became more fluent, expanded their vocabulary, and used well-formed sentences. They also developed their listening skills and appropriate use of their non-verbal communication. Notwithstanding, no progress was noticed in the control group.

The results of the experimental and control groups before and after treatment are presented in the following figure.
If compared with impromptu talks, the traditional method of teaching, in-class oral presentations, was not a success. In Group 2, many students chose some impertinent topics with highly unintelligible, technical terms; in addition, their presentations were long and not properly structured. Some students passively read their manuscripts without even looking at the audience. As a result, most of the presentations became time-consuming, especially with technical problems, which made some students feel uncomfortable while presenting. Accordingly, the audience got bored and passive, and some just departed before the end of the session time. In general, students lost their interest in communicating and showed low motivation to participate in discussions. Most of them were keeping silent and only a few students were engaged. 


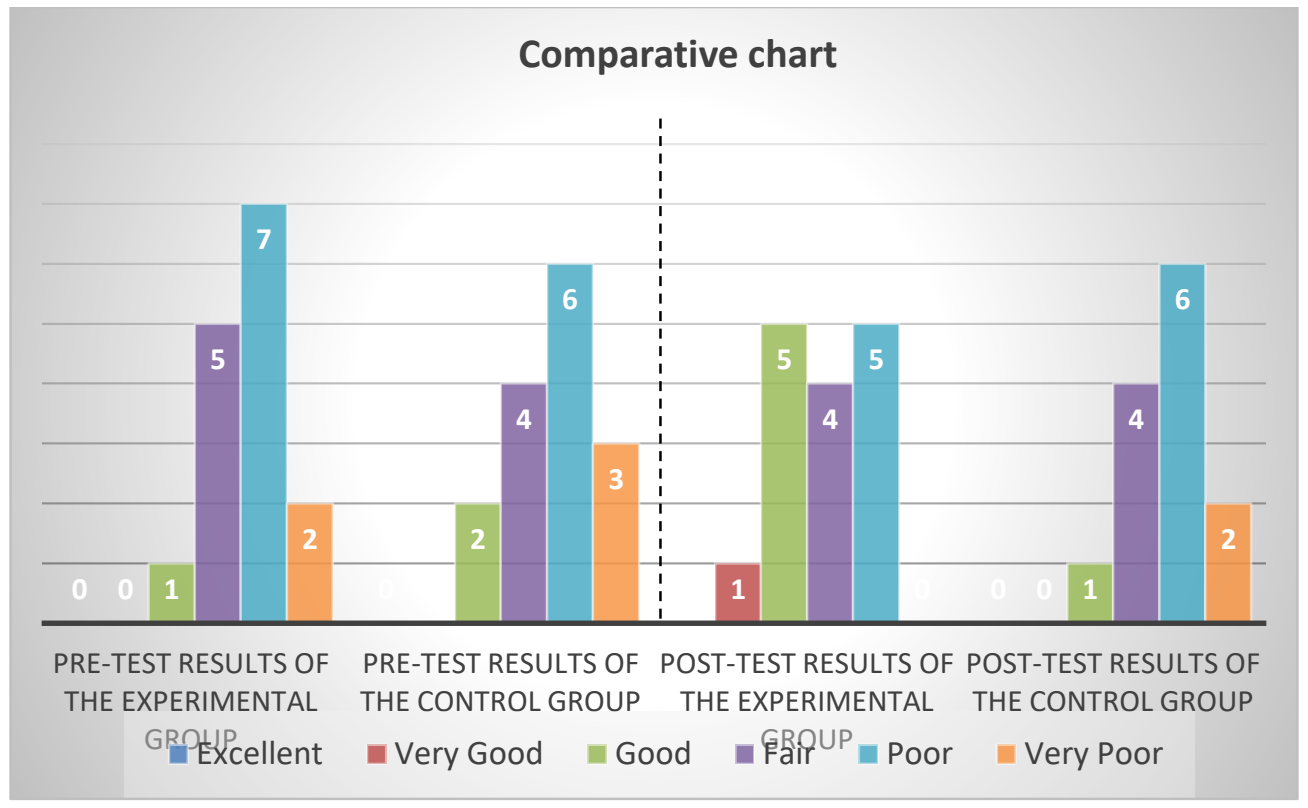

Fig.5: Pre and post-test results of experimental and control groups

However, impromptu talks' topics, proposed by the instructor and/or students, fell under students 'concern and also met their needs. These topics, which are more relevant to contemporary life and communicated in a simple, clear language, heighten students' interest. While a student was delivering their spontaneous speech, others actively listened to them and eagerly provided feedback. They actively involved in and enjoyed different speaking activities. Accordingly, all the students who attended the course, be they regular attendees or not, were given more chances to speak and more individualized attention. Though they belonged to a large class, students were more likely to organize and deliver cogent opinions supported by facts, listen actively to their classmates' viewpoints, develop culturally appropriate use of eye contact and body language and reduce speech apprehension.

Students significantly showed great motivation, engagement, and commitment to learn and hone their oral communication skills as they took their instructor's as well as their classmates' comments and remarks into account. Consequently, the atmosphere in the whole class became alive and conducive. Speaking became fun and less difficult to them. Accordingly, students, who did not regularly attend oral communication course, including some students of Group 2, preferred to attend Group 1.

It is worth noting that at the beginning of the semester, students were too nervous and sometimes shocked when appointed to give an off-the-cuff speech as they were not accustomed to speaking spontaneously in English. Afterwards, they became relatively more confident in delivering their speech, could speak better in a real life conversation, elaborated the topic in a good way, and became more confident after experiencing impromptu talks several times. It was thanks to impromptu speech that students could successfully develop and display their competencies as good oral communicators.

\section{CONCLUSION}

The present study emphasizes that impromptu speech is more effective to large cohorts for enhancing oral communication skills. It hones their speaking as well as listening skills and develops their appropriate use of nonverbal communication. It improves their creativity in developing logical ideas and arranging well-formed sentences. More importantly, it intensely helps students reduce stage fright and speech apprehension. Implementing this kind of speech gives students more energy and motivation and keeps them actively engaged in their course.

In the light of the results of the present study, it is recommended that impromptu speech be implemented in Oral Communication course as a prerequisite not only because it enhances students' communication oral competencies but also because it offers students a conducive atmosphere in which they continuously show up their enthusiasm and interest. It should also be implemented in different courses for at least ten minutes. In fact, it provides skills that go beyond speaking and listening, it develops higher order thinking skills which involve more cognitive processing. 


\section{REFERENCES}

[1] Aliyu, M. (2017).“Developing Oral Communication Skills through Collaborative Learning: Implications for NigerianTeachers". International Journal of English Literature and Social Sciences, 2 (5), 127-130.

[2] Alwright, D. (1994). "The Importance of Interaction in Classroom Language Learning”. Applied Linguistics, 5 (2), 156-171.

[3] Anderson, J. R. (2008). Learning and Memory: An Integrated Approach. New York: John Wiley\& Sons.

[4] Ayres, J. et al. (1998). "Coping with Speech Anxiety: The Power of Positive Thinking". Communication Education, 37 (4), 289-296.

[5] Bailey, K. M. (2005). "Speaking". In D. Nunan (Ed.). Practical English Language Teaching. Singapore: McGraw-Hill.

[6] Barruansyah, R. (2018). "Applying Impromptu Speech Technique to Improve Students' Speaking Ability at the Fourth Semester Students of STIBA Persada”. Journal of English for Academic. 5 (2), 57-72.

[7] Billings, A.C. and Billings, A.C. (2000). Pedagogical and Practical Applications of Coaching a Limited Preparation Event. The Rostrum, 76 (1), 31, 38, 67.

[8] Brown, H.D. (1994). Teaching by Principles: An Interactive Approach to Language Pedagogy. The United States of America: Tina Carver.

[9] Brown, S.W. and E Bennett.(2002). "The Role of Practice and Automaticity in Temporal and Nontemporal Dual-task Performance". Psychological Research, 66 (1), 80-89.

[10] Bryrne, D. (1986). Teaching Oral English. $2^{\text {nd }}$ ed., London: Longman.

[11] El Mortaji, L. (2017)."Effects of Sustained Impromptu Speaking on Public Speaking Anxiety Reduction". Journal of Emerging Trends in Educational Research and Policy Studies, 8 (4), 216-222.

[12] Ford-Brown, L. A. (2014). DK Guide to Public Speaking. Boston: Pearson.

[13] Girardelli, D. (2017). Impromptu Speech Gamification for ESL/EFL Students, Communication Teacher, 31 (3), 156161.

[14] Goffman, E. (1981). Forms of Talk. Oxford : Basil Blackwell.

[15] Goh, C. (2007). Teaching Speaking in the Language Classroom. Singapore: SEAMEO Regional Language Centre.

[16] Hetherington, M.S. (1982). "The Importance of Oral". College English, 44 (6), 570-574.

[17] Hernderson, D. (1982). "Impromptu Speaking as a Tool".Jalt Journal, 4, 75-87.

[18] Lumettu, and T. L. Runtuwene (2018). "Developing the Students' English Speaking Ability through Impromptu Speaking Method".Journal of Physics Conference Series, 953 (1), 1-9.

[19] Mahmud, M. M. (2014)."Communication Aptitude and Academic Success".Procedia - Social and Behavioral Sciences, 134, 125-133.
[20] Mbeh, A.T. (2017). "Impromptu Speaking and Authentic Assessment in English Language Teaching/Learning". International Journal of New Technology and Research, 3 (3), 11-16.

[21] Mehrabian, A. and S.Ferris.(1967). "Inference of Attitudes from Nonverbal Communication in Two Channels".Journal of Consulting Psychology, 31, 248-252..

[22] Moors, A., \& De Houwer, J. (2006). "Automaticity: A Theoretical and Conceptual Analysis". Psychological Bulletin, 132(2), 297-326.

[23] Preston, C. T. (1990). "Literal and Metaphorical Advocacy: Differentiating the Limited Preparation Speaking Events. Argumentation and Advocacy, 27(1), 14-24.

[24] Rahman, M. (2010). “Teaching Oral Communication Skills: A task-based Approach”. English for Specific Purposes World, 9 (1), 1-11.

[25] Staab, C. (1992). Oral Language for Today's Classroom.Toronto: Pippin Publishing.

[26] Sekkal, K. (2020). "Listening Comprehension for "Business English" Students; Obstacles, Needs, and Strategies". International Journal of Linguistics, Literature and Translation, 3 (1), 36-46.

[27] Smith, T.E. and A.B. Frymier (2007).“Get 'Real': Does Practicing Speeches Before an Audience Improve Performance?"Communication Quarterly, 54 (1),111-125.

[28] Syakur, A.(1987). The Component of Speaking. Boston: Allin and Bacon. University Press.

[29] Tsang, A. (2017). "Enhancing Learners' Awareness of Oral Presentation (Delivery) Skills in the Context of Selfregulated Learning". Active Learning in Higher Education, $21(1), 39-50$ 